Unfallchirurg 2012 $\cdot 115: 98-99$

DOI 10.1007/s00113-011-2117-4

๑) Springer-Verlag 2012

\section{F. Gebhard}

Center for Surgery Department for Orthopaedic Trauma, Hand- and Reconstructive Surgery, Orthopaedic Trauma, Ulm University, Ulm

\title{
Moderne intraoperative Bildgebungsverfahren, Teil I
}

Die Anwendung einer intraoperativen Röntgendurchleuchtung in Form eines C-Bogens gehört zum unfallchirurgischen Standard.

Zurückblickend muss man sagen, dass dies eine Technologie ist, die bisher nicht mal 80 Jahre der Chirurgie zur Verfügung steht und sich dennoch zu einem unverzichtbaren Instrument in moderner Orthopädie und Unfallchirurgie entwickelt hat.

\section{》) Moderne intraoperative Bildgebungsverfahren haben sich zu einem unverzichtbaren Instrument in Orthopädie und Unfallchirurgie entwickelt}

Parallel hierzu haben sich Röntgendiagnostiksysteme rasant entwickelt, sodass im täglichen Arbeitsumfeld eine zunehmende Menge hoch qualitativer Bilder im 2D- und 3D-Format dem Chirurgen zur Verfügung gestellt werden. Mehr und mehr kann diese Technologie auch unmittelbar im Operationssaal genutzt werden.

In diesem Heft möchten wir den derzeitigen Stand der technischen Entwicklung für intraoperative Bildgebung näher darlegen.

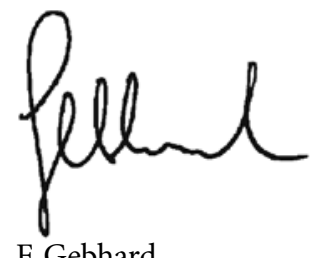

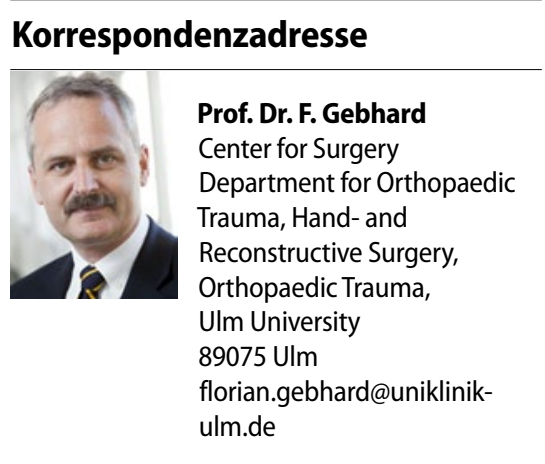


Hier steht eine Anzeige.

黛 Springer 